\title{
Inocuidade micotoxicológica e viabilidade de Aspergillus spp. com potencial probiótico provenientes do trato digestório bovino
}

\author{
[Mycotoxicological safety and viability of Aspergillus spp.with probiotic potential from the \\ bovine digestive tract $]$ \\ F.O. Abrão ${ }^{1}$, E.R. Duarte ${ }^{2 *}$, M.S. Pessoa ${ }^{3}$, V. L. Santos ${ }^{4}$, N.M. Rodriguez ${ }^{4}$ \\ ${ }^{1}$ Instituto Federal Goiano - Ceres, GO \\ ${ }^{2}$ Universidade Federal de Minas Gerais - Montes Claros, MG \\ ${ }^{3}$ Universidade Federal de Goiás - Goiânia, GO \\ ${ }^{4}$ Universidade Federal de Minas Gerais - Belo Horizonte, MG
}

\section{RESUMO}

Objetivou-se, com a presente pesquisa, avaliar a viabilidade de Aspergillus spp. com potencial probiótico durante o armazenamento e diante da pressão da microbiota autóctone, bem como a tolerância aos principais ácidos graxos da fermentação ruminal. Verificou-se também a inocuidade micotoxicológica desses isolados fúngicos cultivados em meio de cultivo sólido. Foram avaliados 20 isolados de Aspergillus spp., provenientes do trato gastrointestinal de bovinos criados em Urochloa decumbens lignificada. Esses fungos foram identificados por análise de sequências do DNAr e foram selecionados por apresentarem expressivo potencial celulolítico. O método vapor de amônia foi utilizado para detecção de cepas produtoras de micotoxinas. Os isolados foram avaliados quanto à viabilidade de crescimento em fluido ruminal por até 96 horas e estocagem em condições ambientais. Observou-se que os fungos avaliados não produziram aflatoxinas e que $95 \%$ dos isolados apresentaram resistência aos ácidos ruminais. Dois isolados, selecionados a partir das análises anteriores, apresentaram viabilidade sob a pressão da microbiota autóctone e de metabólitos do ecossistema ruminal e permanecem viáveis por, no mínimo, dois anos. Conclui-se que os isolados do gênero Aspergillus selecionados nesta pesquisa apresentam características fisiológicas para serem utilizados com aditivos microbianos ou probióticos para o ambiente ruminal.

Palavras-chave: aditivo microbiano, ácidos graxos voláteis, micotoxinas, probióticos, bovinocultura

\begin{abstract}
The aims in this study were to evaluate the viability of Aspergillus spp. with probiotic potential during storage, pressure of autochthonous microbiota and tolerance to the main fatty acids of ruminal fermentation. The mycotoxicological safety was also verified. Twenty isolates from the gastrointestinal tract of cattle raised in lignified Urochloa decumbens were identified by rDNA sequence analysis and were previously selected because they showed significant cellulolytic potential. The ammonia vapor method was used to detect the production of mycotoxins. The isolates were evaluated for viability of ruminal fluid growth for up to 96 hours and storage under environmental conditions. The evaluated fungi did not produce aflatoxins, and 95\% of them had resistance to ruminal acids. Two isolates, selected according these tests, presented viability on autochthonous microbiota pressure and metabolites from the ruminal ecosystem and remain viable for at least two years. In this research, the selected Aspergillus spp. isolates present physiological characteristics to be used with microbial additives or probiotic.
\end{abstract}

Keywords: microbial additive, volatile fatty acids, mycotoxins, probiotic, cattle

Recebido em 2 de março de 2017

Aceito em 14 de fevereiro de 2018

*Autor para correspondência (corresponding author)

E-mail: duartevet@pq.cnpq.br 


\section{INTRODUÇÃO}

Recentemente, tem-se observado o aumento da preocupação dos consumidores com a segurança e a qualidade de produtos de origem animal. Por isso, cada vez mais, buscam-se aditivos naturais que visem ao aumento da produtividade animal e à diminuição da transferência de patógenos zoonóticos e de resíduos de antimicrobianos em produtos de origem animal (Morais et al., 2011). A suplementação de probióticos ou aditivos microbianos na dieta animal pode representar alternativa para substituição dos antibióticos na pecuária, por não gerarem resíduos tóxicos na carne e no leite e não favorecerem a resistência microbiana (Abrão et al., 2012).

Os aditivos alimentares microbianos são fonte de microrganismos vivos (viáveis) e incluem: bactérias, fungos e leveduras. As espécies mais importantes e comumente utilizadas na dieta de ruminantes são as leveduras Saccharomyces cerevisiae e o fungo Aspergillus oryzae (Goes et al., 2005).

Os probióticos são suplementos alimentares constituídos por microrganismos vivos que favorecem o equilíbrio da microbiota autóctone, contribuindo para o melhor desempenho e imunidade dos hospedeiros (Annuk et al., 2003; Fao 2002; Zábransky et al., 2016). Devem estar presentes como células viáveis, capazes de sobreviver, ser estáveis e capazes de permanecer viáveis por longos períodos sob condições de armazenamento a campo, e finalmente não devem ser patogênicos ou tóxicos (Annuk et al., 2003; Fao 2002).

Em ruminantes, além da capacidade desejável de o microrganismo probiótico degradar componentes da célula vegetal, esse deve participar ativamente do processo de digestão e fermentação ruminal, melhorando a utilização de forragens (Wallace, 1994).

Fungos anaeróbios facultativos do rúmen destacam-se pela produção superior de enzimas (Almeida et al., 2014; Abrão et al., 2017). A elaboração de novos aditivos microbianos contendo esses fungos permitirá maior oferta desses produtos no mercado agropecuário, com inclusão de microrganismos mais eficientes na modulação ruminal, já que a maioria dos aditivos microbianos comerciais utiliza microrganismos que não são próprios do ecossistema ruminal, como as leveduras Saccharomyces cerevisiae.

Nesta pesquisa, foram avaliadas a viabilidade de Aspergillus spp. com potencial probiótico durante o armazenamento e diante da pressão da microbiota autóctone, a inocuidade micotoxicológica e a tolerância aos principais ácidos graxos da fermentação ruminal.

\section{MATERIAL E MÉTODOS}

Vinte isolados de fungos do gênero Aspergillus provenientes do trato gastrointestinal de bovinos mestiços Nelore, criados no Norte de Minas Gerais, foram selecionados por apresentarem capacidade superior de produção de enzimas de degradação da parede celular (Abrão et al., 2014) e foram caracterizados neste estudo (Tab. 1). Esses fungos foram isolados em meio contendo celulose microcristalina como única fonte de carbono e foram identificados com base nas análises das sequências do rDNA (Abrão et al., 2014). Os procedimentos adotados com os animais foram aprovados pela Comissão de Ética no Uso de Animais da UFMG/ protocolo $188 / 2013$.

Tabela 1. Descrição da origem e identificação molecular dos isolados fúngicos avaliados neste estudo

\begin{tabular}{lccc}
\multicolumn{1}{c}{ Espécies } & Isolados $(\mathrm{n}=20)$ & Hospedeiros & Sítio \\
\hline Aspergillus fumigatus & AF90 & Vaca & Rúmen \\
Aspergillus terreus & AT17, AT22 & Novilho & Rúmen \\
Aspergillus terreus & AT15, AT79 & Novilho & Ampola retal \\
Aspergillus niger & AN83 & Novilho & Ampola retal \\
Aspergillus terreus & AT13, AT40, AT43, AT46, AT51, AT52, AT53 & Bezerro & Rúmen \\
Aspergillus niger & AN54 & Bezerro & Rúmen \\
Aspergillus terreus & AT7, AT8, AT42, AT45, AT50 & Bezerro & Ampola retal \\
Aspergillus fumigatus & AF69 & Bezerro & Ampola retal \\
\hline
\end{tabular}


O método vapor de amônia foi utilizado para identificação de cepas produtoras e não produtoras de micotoxinas, conforme descrito por Saito e Machida (1999). Cada isolado fúngico, em triplicata, foi inoculado no centro da placa de Petri, com meio de cultura ágar dextrose batata (BDA). Após incubação de cinco dias em estufa a $37^{\circ} \mathrm{C}$, adicionaram-se, nas tampas das placas, $2 \mathrm{~mL}$ de solução de hidróxido de amônio $\left(\mathrm{NH}_{4} \mathrm{OH}\right) 25 \%$. Posteriormente as placas foram vedadas e incubadas invertidas em estufa a $37^{\circ} \mathrm{C}$ por mais 24 horas. Após esse período, as placas foram retiradas da estufa e foi observada a coloração da base das colônias crescidas em comparação a uma placa controle (sem adição de $\mathrm{NH}_{4} \mathrm{OH}$ ) (Saito e Machida, 1999). Fungos produtores de micotoxinas apresentam alteração na coloração no verso da colônia após a adição da amônia (Baptista et al., 2004).

Para avaliar a tolerância dos isolados fúngicos diante dos principais ácidos graxos voláteis do rúmen, $10 \mathrm{~mL}$ de uma mistura contendo ácidos graxos voláteis (AGVs) foram adicionados a $990 \mathrm{~mL}$ de caldo Sabouraud. A concentração final de AGVs no meio foi de 101,4; 31,4 e 23,4 mmol $\mathrm{L}^{-1}$ de ácidos acético, propiônico e butírico, para uma proporção de 65:20:15 desses ácidos, respectivamente. Um mililitro de solução contendo cada isolado testado (inóculo padronizado para $10^{11}$ esporos. $\mathrm{mL}^{-1}$ ) foi adicionado a $9 \mathrm{~mL}$ da mistura descrita anteriormente, a qual foi incubada a $39^{\circ} \mathrm{C}$, em microaerofilia (Nooraee et al., 2010). Também foram avaliadas as proporções 72:20:8 e 50:40:10, simulando as proporções ruminais de AGVs para animais recebendo exclusivamente volumoso e para animais confinados e alimentados com alta proporção de concentrado na dieta. $\mathrm{O}$ pH do meio foi ajustado para 6,5 com a utilização de $\mathrm{NaOH}$ 5mol. $\mathrm{L}^{-1}$.

A densidade óptica (DO) de cada cultura foi avaliada com zero, 24 e 96 horas de incubação, utilizando-se espectrofotômetro a $530 \mathrm{~nm}$, conforme método adaptado de Nooraee et al. (2010). O valor da $\mathrm{DO}_{530 \mathrm{~nm}}$ foi comparado com o valor médio da leitura de um grupo controle (sem AGV). Ao final de cada tempo, $1 \mathrm{~mL}$ de cada tubo contendo a solução acrescida do inóculo microbiano foi plaqueada em meio ágar Sabouraud para se verificar a viabilidade da biomassa fúngica
O delineamento experimental foi o inteiramente ao acaso. Após análise de exploratória dos dados, foi realizada a comparação dos tratamentos pela aplicação do teste não paramétrico KruskallWallis, a 5\% de significância, com auxílio do pacote estatístico ASSISTAT 7.7 Beta (Silva, 2014).

Para avaliar a viabilidade no armazenamento em condições ambientais, cada isolado foi cultivado, inicialmente, em tubos contendo meio celulose inclinado e incubado em estufa por, aproximadamente, sete dias. Ao esporular, foram adicionadas alíquotas de solução salina acrescida de Tween $20 ®$ a $1 \%$ para ressuspensão dos esporos. A padronização dos inóculos ocorreu com a escala 3 no padrão Mac Farland e absorbância (abs) 0,35-0,55 em espectrofotômetro. Imediatamente, $1 \mathrm{~mL}$ da suspensão foi diluído e plaqueado pela técnica de Pour plate em meio ágar Sabouraud, para quantificação de unidades formadoras de colônicas (UFC) por mL.

A suspensão preparada de esporos foi armazenada em tubos de ensaio, no interior de um frasco protegido de luz, em temperatura ambiente (média de $22^{\circ} \mathrm{C}$ ), por até dois anos. Mensalmente, durante dois anos, para verificar a viabilidade da solução de esporos, foi realizada diluição seriada, e uma alíquota da diluição $10^{11}$ foi semeada em placa de Petri com meio Sabouraud. Posteriormente, as placas seguiram para estufa a $39^{\circ} \mathrm{C}$ e permaneceram por até sete dias para leitura do desenvolvimento das colônias fúngicas.

$\mathrm{O}$ delineamento foi inteiramente ao acaso, sendo que cada isolado fúngico representou uma repetição e os meses constituíram os tratamentos, totalizando 460 observações. Os dados foram submetidos à análise de regressão, com um nível de significância de 5\% em software estatístico ASSISTAT 7.7 Beta (Silva, 2014).

Para verificar a viabilidade e a capacidade de multiplicação dos inóculos fúngicos em associação com a microbiota autóctone ruminal, realizou-se o teste de recuperação dos fungos ao longo de diferentes tempos de incubação. Dois fungos destacaram-se em ensaios quanto à produção de enzimas do complexo lignolítico, celulases e xilanases (AT13 e AF69) e nas etapas anteriores deste estudo e, dessa forma, foram selecionados, cultivados em meio celulose e 
mantidos em estufa a $39^{\circ} \mathrm{C}$ por sete dias, até esporulação. Os esporos foram ressuspendidos em solução salina estéril acrescida de Tween $20 \circledR$ a $1 \%$ e padronizados em escala de Mac Farland 1 para concentração de $10^{5}$ esporos. $\mathrm{mL}^{-1}$. Em triplicata, 0,5mL de solução de cada inóculo foi adicionado em frascos contendo $4 \mathrm{~mL}$ de fluido ruminal e $2,5 \mathrm{~mL}$ de meio de cultura tampão (Abrão, 2016).

Posteriormente, os frascos foram incubados em termoshaker com agitação orbital a $39^{\circ} \mathrm{C}$. O fluido ruminal foi obtido de dois bovinos fistulados, alimentados com Urochoa decumbens como única fonte de volumoso. Um grupo controle também foi avaliado com adição de $0,5 \mathrm{~mL}$ de solução salina estéril em substituição ao inóculo padronizado nos frascos.

Após 18, 24, 48, 72 e 96 horas, foram retiradas alíquotas de $1 \mathrm{~mL}$ dos respectivos frascos e realizadas diluições sequenciais e inóculos cultivados em meio ágar Sabouraud. Swabs também foram imersos em cada frasco e estriados em placas contendo o mesmo meio descrito anteriormente. Os materiais foram incubados em BOD $\left(39^{\circ} \mathrm{C}\right)$ por até sete dias para observação do desenvolvimento das colônias.

Os fungos crescidos no meio de cultura que apresentaram morfotipologia semelhante ao isolado fúngico inoculado foram cultivados em tubos contendo o ágar Sabouraud para posterior identificação por análises das sequências do rDNA conforme descrito em Abrão et al. (2014) para fungos filamentosos. Oito isolados semelhantes ao morfotipo AF69 e 11 isolados semelhantes ao morfotipo AT13 foram reisolados e identificados por essa técnica. Os resultados foram avaliados por meio de estatística descritiva.

\section{RESULTADOS E DISCUSSÃO}

A produção de micotoxinas não foi evidenciada para os isolados avaliados indicando-os como seguros quanto a esse aspecto. Os requisitos nutricionais e fisiológicos relacionados com a produção de micotoxinas são geralmente muito mais específicos do que aqueles relacionados com o crescimento do fungo. Além disso, sabese que, dentre muitas espécies, nem todos os indivíduos são capazes de produzir toxinas (Soriano; Burdaspal, 2007).

Estudos têm indicado que as espécies Aspergillus niger, Fusarium solani, Penicillium fumiculosum e $P$. rubrum podem apresentar ação antagônica ao A. flavus, produtor de aflatoxinas. O crescimento de A. flavus é suprimido em cultura mista com Rhizopus stolonifer, $R$. oryzae, Saccharomyces cerevisiae (probiótico) e Brevibacterium linens, mas é estimulado por Acetobacter aceti (Baptista et al., 2004). Este relato é relevante, visto que uma das espécies isolada neste trabalho ( $A$. niger), além de não ter produzido micotoxinas, poderia auxiliar no controle de organismos micotoxigênicos, como o A. flavus, sendo essa outra característica desejável a um probiótico, que deve ser avaliada em futuros estudos.

Após 24h de incubação, os 20 isolados avaliados apresentaram melhor desenvolvimento na ausência de AGVs $(\mathrm{P}<0,05)$ e incubados na proporção de 65:20:15, quando comparados às demais proporções avaliadas desses ácidos. A proporção 65:20:5 dos AGVs é normalmente encontrada no ambiente ruminal de animais alimentados com razão volumoso/concentrado de 50:50 ou 60:40 e possivelmente proporcionou aos isolados avaliados um menor período de adaptação (fase Lag). No período inicial de incubação, os isolados apresentaram desenvolvimento inferior nas proporções 50:40:10 e 72:20:8, (Tab. 2). Essas proporções são observadas no ambiente ruminal de bovinos alimentados com dietas com alta inclusão de concentrado ou contendo somente volumoso, respectivamente (Goularte et al., 2011).

Os AGVs produzidos no rúmen são a principal fonte de energia para os ruminantes e são gerados na fermentação microbiana dos alimentos. Os ácidos acético, propiônico e butírico são os principais $\mathrm{AGVs}$ produzidos e podem prover até $80 \%$ da exigência diária de energia dos ruminantes. A população microbiana do rúmen geralmente converte os carboidratos fermentados em 60 a $70 \%$ de ácido acético, 18 a $22 \%$ de ácido propiônico e 13 a $16 \%$ de ácido butírico, mas essa proporção depende do tipo de dieta e da população microbiana envolvida (Goularte et al., 2011). 
Tabela 2. Crescimento de Aspergillus spp. em diferentes proporções de AGVs (acético:propiônico:butírico), considerando-se a densidade óptica a 530nm, após diferentes períodos de incubação

\begin{tabular}{ccccc}
\hline & \multicolumn{4}{c}{ Proporção de ácidos graxos voláteis (AGVs) } \\
\cline { 2 - 5 } Tempo & DO - Sem AGVs & DO - 65:20:15 & DO - 72:20:08 & DO - 50:40:10 \\
\hline $0 \mathrm{~h}$ & $0,2332 \mathrm{Ca}$ & $0,2357 \mathrm{Ca}$ & $0,2397 \mathrm{Ca}$ & $0,2385 \mathrm{Ca}$ \\
$24 \mathrm{~h}$ & $0,2844 \mathrm{Ba}$ & $0,2993 \mathrm{Ba}$ & $0,2626 \mathrm{Bb}$ & $0,2509 \mathrm{Bb}$ \\
$96 \mathrm{~h}$ & $0,5067 \mathrm{Aa}$ & $0,5278 \mathrm{Aa}$ & $0,5094 \mathrm{Aa}$ & $0,4509 \mathrm{Aa}$ \\
\hline
\end{tabular}

Nota: Letras minúsculas diferentes nas linhas e maiúsculas nas colunas indicam diferenças estatísticas pelo teste de Kruskall-Wallis $(\mathrm{P}<0,05) ; *$ AGVs = ácidos graxos voláteis: acético, propiônico e butírico. $\mathrm{DO}=$ densidade óptica.

O tempo de $96 \mathrm{~h}$ de incubação proporcionou melhor desenvolvimento para todos os isolados avaliados nas diferentes proporções de AGV avaliadas (Tab. 2). Todos os isolados apresentaram-se viáveis após incubação em meio Sabouraud, com exceção do isolado AT15 na proporção 50:40:10, que simula dietas com alta proporção de concentrado.

Nesta pesquisa, verificou-se a capacidade de sobrevivência para diferentes simulações de condições do ambiente ruminal para a maioria dos isolados, o que sugere a possibilidade da utilização desses fungos como aditivos microbianos ou probióticos ruminais. Poucas são as pesquisas desenvolvidas na elaboração de aditivos microbianos alternativos que consideram a tolerância a AGVs. Nooraee et al. (2010) caracterizaram a levedura Kluyveromyces marxianus quanto às propriedades probióticas. Não obstante, constataram que as cepas avaliadas apresentaram tolerância aos principais ácidos graxos voláteis do rúmen, como reportado neste presente estudo.

Todos os inóculos avaliados permaneceram viáveis durante os dois anos de análises em condições ambientais. A média de $10^{11}$ UFC. $\mathrm{mL}^{-1}$ de solução não foi influenciada pelo tempo de armazenamento (Tab. 3, P>0,05). Isso indicaria o potencial do inóculo para administração ao longo de até 24 meses.

Tabela 3. Concentração de unidades formadoras de colônia por mL (UFC.mL ${ }^{-1}$ ) de Aspergillus spp. provenientes do trato digestório de bovinos estocados em temperatura ambiente

\begin{tabular}{ccccccc}
\hline & \multicolumn{5}{c}{ Tempo em meses } \\
\cline { 2 - 7 } Concentrações & 0 & 2 & 4 & 6 & 12 & 24 \\
\hline Média & $2,9 \times 10^{11}$ & $2,8 \times 10^{11}$ & $2,8 \times 10^{11}$ & $2,7 \times 10^{11}$ & $3,0 \times 10^{11}$ & $1,8 \times 10^{11}$ \\
Mínimo & $1,0 \times 10^{11}$ & $1,0 \times 10^{11}$ & $1,0 \times 10^{11}$ & $1,0 \times 10^{11}$ & $1,0 \times 10^{11}$ & $1,0 \times 10^{11}$ \\
Máximo & $6,0 \times 10^{11}$ & $6,0 \times 10^{11}$ & $6,0 \times 10^{11}$ & $6,0 \times 10^{11}$ & $6,0 \times 10^{11}$ & $6,0 \times 10^{11}$ \\
\hline
\end{tabular}

Ambos os isolados, AT13 e AF69, previamente selecionados mantiveram-se viáveis até 96 horas de incubação em fluido ruminal bovino (Tab. 4). Esses isolados foram recuperados nos respectivos tubos de inoculação apresentando as

Tabela 4. Quantificação de isolados de Aspergillus spp. em unidades formadoras de colônia por $\mathrm{mL}$ em diferentes tempos de incubação in vitro em fluido ruminal bovino

\begin{tabular}{cccccc}
\multicolumn{6}{c}{ diferentes tempos de incubação in vitro em fluido ruminal bovino } \\
\cline { 2 - 6 } Isolados & 18 & 24 & 48 & 72 & 96 \\
\cline { 2 - 6 } Controle & $1,2 \times 10^{5}$ & $7,0 \times 10^{4}$ & $1,0 \times 10^{4}$ & $1,0 \times 10^{4}$ & $1,0 \times 10^{4}$ \\
AT13 & $1,0 \times 10^{6}$ & $1,0 \times 10^{6}$ & $1,0 \times 10^{6}$ & $2,3 \times 10^{5}$ & $2,4 \times 10^{5}$ \\
AF69 & $6,0 \times 10^{5}$ & $6,1 \times 10^{5}$ & $2,0 \times 10^{6}$ & $6,6 \times 10^{5}$ & $1,0 \times 10^{6}$ \\
\hline
\end{tabular}

Nota: AT13 refere-se ao fungo Aspergillus terreus; AF69 refere-se ao fungo Aspergillus fumigatus.

Para os tubos inoculados, observou-se o predomínio do morfotipo do fungo adicionado em cada placa de cultivo no reisolamento. A identificação molecular dos isolados recuperados confirmou a mesma espécie inoculada com características morfológicas de crescimento, e as respectivas espécies foram confirmadas por análise do sequenciamento do DNAr (Abrão et al., 2014). dois fungos selecionados apresentaram viabilidade sob a pressão da microbiota autóctone do rúmen e na presença de metabólitos ruminais. 
Tabela 5. Identificação por sequenciamento dos fragmentos do DNAr de fungos filamentosos reisolados do trato gastrointestinal de bovinos de corte criados em pastagens tropicais

\begin{tabular}{lcccc}
\hline $\begin{array}{c}\text { Identificação } \\
\text { proposta }\end{array}$ & $\begin{array}{c}\text { Número de } \\
\text { reisolados }\end{array}$ & $\begin{array}{c}\text { Identidade } \\
(\%)\end{array}$ & $\begin{array}{c}\text { Query } \\
\text { coverage } \\
(\%)\end{array}$ & $\begin{array}{c}\text { Resultados do BLAST [n }{ }^{\circ} \text { acc. GenBank] e } \\
\text { cepas de referência }\end{array}$ \\
\hline $\begin{array}{l}\text { Aspergillus } \\
\text { fumigatus } \\
\begin{array}{l}\text { Aspergillus } \\
\text { terreus }\end{array}\end{array}$ & 8 & 100 & 100 & $\begin{array}{c}\text { Aspergillus fumigatus } \text { [KJ175459.1], } \\
\text { ATCC 208997 }\end{array}$ \\
\hline
\end{tabular}

\section{CONCLUSÕES}

Nesta pesquisa, foram selecionados dois isolados de Aspergillus spp., provenientes do TGI de bovinos, não produtores de micotoxinas, tolerantes a diferentes proporções de ácidos graxos voláteis do rúmen e viáveis após incubação de 96 horas sob pressão da microbiota ruminal e quando estocados em solução salina por até dois anos. Essas características, aliadas ao potencial celulolítico desses isolados, apontam o potencial desses fungos para serem utilizados como probióticos para bovinos alimentados com forragens tropicais.

\section{AGRADECIMENTOS}

Ao Conselho Nacional de Desenvolvimento Científico e Tecnológico (CNPq), à Fundação de Amparo à Pesquisa de Minas Gerais (Fapemig), à Coordenação de Aperfeiçoamento de Pessoal de Nível Superior (Capes, Brasil), à Pró-Reitoria de Pesquisa da Universidade Federal de Minas Gerais e ao Instituto Federal Goiano (IF Goiano - PROPPI).

\section{REFERÊNCIAS}

ABRÃO F.O.; DUARTE E.R.; PESSOA, M.S. et al. Notable fibrolytic enzyme production by Aspergillus spp. isolates from the gastrointestinal tract of beef cattle fed in lignified pastures. PLoS One. v.29, P.e0183628. 2017. Availalble in: <http://journals.plos.org/plosone/article?id=10.1 371/journal.pone.0183628>. Accessed in: 01 Nov. 2017.

ABRÃO, F.O. Fungos do trato digestório de ruminantes como potencial probiótico para bovinos alimentados com forrageiras lignificadas. 2016. 137f. Tese (Doutorado em Nutrição Animal). - Escola de Veterinária, Universidade Federal de Minas Gerais, Belo Horizonte, MG.
ABRÃO, F.O.; DUARTE, E.R.; ROSA, C.A. $e t$ al. Characterization of fungi from ruminal fluid of beef cattle with different ages and raised in tropical lignified pastures. Curr. Microbiol., v.69, p.1-13, 2014.

ABRÃO, F.O.; PESSOA, M.S.; FREITAS, C.E.S. et al. Potencialidade e limitações da utilização de aditivos na produção de bovinos de corte. Cad. Ciên. Agrár., v.4, p.49-60, 2012.

ALMEIDA, P.N.M.; FREITAS, C.E.S.; ABRÃO, F.O. et al. Atividade celulolítica de fungos isolados do rúmen de bovinos leiteiros alimentados com forragens tropicais. Rev. Caatinga, v.27, p.202-207, 2014.

ANNUK, H.; SHCHEPETOVA, J.; KULLISAAR, T. et al. Characterization of intestinal lactobacilli as putatite probiotic candidates. J. Appl. Microbiol., v.94, p.403-412, 2003.

BAPTISTA, A.S.; HORII, J.; BAPTISTA, A.S. Fatores físico-químicos e biológicos ligados à produção de micotoxinas. Bol. CEPPA, v.22, p.1-14, 2004.

FOOD and Agriculture Organization of the United Nations; Who World Health Organization. Working group report on drafting guidelines for the evaluation of probiotics in food London. Ontario: FAO, 2002.

GOES, R.H.T.B.; ALVES, D.D.; VALADARES FILHO, S.C.; MARSON, E.P. Utilização de aditivos alimentares microbianos na alimentação de bovinos de corte e leite: revisão. Arq. Ciênc. Vet. Zool., v.8, p.47-56, 2005.

GOULARTE, S.R.; ÍTAVO, L.C.V.; SANTOS, G.T. et al. Ácidos graxos voláteis no rúmen de vacas alimentadas com diferentes teores de concentrado na dieta. Arq. Bras. Med. Vet. Zootec., v.63, p.1479-1486, 2011. 
MORAIS, J.A.S.; BERCHIELLI, T.T.; REIS, R.A. Aditivos. In: BERCHIELLI, T.T.; PIRES, A.V.; OLIVEIRA, S.G. Nutrição de ruminantes. 2ed. Jaboticabal: FUNEP, 2011. p.565-591.

NOORAEE, S.E.; ALIMON, A.R.; HO, Y.W.; ABDULLAH, N. Characterization of Kluyveromyces marxianus as a potential feed additive for ruminants. Lett. Appl. Microbiol., v.50, p.578-584, 2010.

SAITO, M.; MACHIDA, S. A rapid identification method for aflatoxin-producing strains of Aspergillus flavus and A. parasiticus by ammonia vapor. Mycoscience, v.40, p.205208, 1999.

SILVA, F.A.S. ASSISTAT. Versão 7.7 Beta DEAGCTRN-UFCG. 2014. Disponível em: <http://www.assistat.com - Atualiz.06/01/2014>. Acessado em: 1 out. 2016.
SORIANO, J.C.; BURDASPAL, P. Aflatoxinas del grupo B y G. En: SORIANO, J. (Ed.). Micotoxinas en 478 alimentos. Madrid: Díaz de Santos, 2007, 396p.

WALLACE, R.J. Ruminal microbiology, biotechnology, and ruminant nutrition: progress and problems. J. Anim. Sci., v.72, p.2992-3003, 1994.

ZÁBRANSKY, L.; HADAČOVÁ, V.; ŠOCH, $M$. et al. Influence of probiotic feed additives on rumen microflora of cattle. J. Anim. Sci. Biotechnol., v.49, p.246-248, 2016. 